\title{
Novel breast cancer risk alleles and interaction with ionizing radiation among U.S. Radiologic Technologists
}

\author{
Parveen Bhatti ${ }^{1}{ }^{\star}, 2$, Michele M. Doody ${ }^{2}$, Preetha Rajaraman ${ }^{2}$, Bruce H. Alexander ${ }^{3}$, \\ Meredith Yeager ${ }^{4}$, Amy Hutchinson ${ }^{4}$, Laurie Burdette ${ }^{4}$, Gilles Thomas ${ }^{4}$, David J. \\ Hunter $^{2,5}$, Steven L. Simon ${ }^{2}$, Robert M. Weinstock ${ }^{6}$, Marvin Rosenstein ${ }^{6}$, Marilyn Stovall ${ }^{7}$, \\ Dale L. Preston ${ }^{8}$, Martha S. Linet ${ }^{2}$, Robert N. Hoover ${ }^{2}$, Stephen J. Chanock ${ }^{2,4}$, and Alice J. \\ Sigurdson ${ }^{2}$ \\ ${ }^{1}$ Program in Epidemiology, Division of Public Health Sciences, Fred Hutchinson Cancer Research \\ Center, Seattle, WA, USA \\ 2Division of Cancer Epidemiology and Genetics, National Cancer Institute, NIH, DHHS, Bethesda, \\ MD, USA \\ ${ }^{3}$ Division of Environmental Health Sciences, School of Public Health, University of Minnesota, \\ Minneapolis, MN, USA \\ ${ }^{4}$ Core Genotyping Facility, Advanced Technology Program, SAIC-Frederick Inc., NCI-Frederick, \\ Frederick, MD, USA \\ ${ }^{5}$ Program in Molecular and Genetic Epidemiology, Department of Epidemiology, Harvard School \\ of Public Health, Boston, MA, USA \\ ${ }^{6}$ Research Triangle Institute, Bethesda, MD, USA \\ ${ }^{7}$ Department of Radiation Physics, The University of Texas M. D. Anderson Cancer Center, \\ Houston, Texas, USA \\ ${ }^{8}$ HiroSoft International Corporation, Seattle, WA, USA
}

\begin{abstract}
As genome-wide association studies of breast cancer are replicating findings and refinement studies are narrowing the signal location, additional efforts are necessary to elucidate the underlying functional relationships. One approach is to evaluate variation in risk by genotype based on known breast carcinogens, such as ionizing radiation. Given the public health concerns associated with recent increases in medical radiation exposure, this approach may also identify potentially susceptible sub-populations. We examined interaction between 27 newly identified breast cancer risk alleles (identified within the NCI Cancer Genetic Markers of Susceptibility and the Breast Cancer Association Consortium genome-wide association studies) and occupational and medical diagnostic radiation exposure among 859 cases and 1083 controls nested within the United States Radiologic Technologists cohort. We did not find significant variation in the radiation-related breast cancer risk for the variant in RAD51L1 (rs10483813) on 14q24.1 as we had hypothesized. In exploratory analyses, we found that the radiation-associated breast cancer risk varied significantly by linked markers in 5p12 (rs930395, rs10941679, rs2067980, and rs4415084) in the mitochondrial ribosomal protein S30 (MRPS30) gene ( $\left.\mathrm{p}_{\text {interaction }}=0.04\right)$. Chance, however, may explain these findings, and as such, these results need to be confirmed in other populations with low to moderate levels of radiation exposure. Even though a complete
\end{abstract}

*Correspondence and reprint requests to: Parveen Bhatti, Program in Epidemiology, Division of Public Health Sciences, Fred Hutchinson Cancer Research Center, Seattle, WA, USA TEL: 206. 667-7803 FAX: 206 667-4787 pbhatti@ fhcrc.org. 
understanding by which these variants may increase breast cancer risk remains elusive, this approach may yield clues for further investigation.

\section{Introduction}

Progress in discovering associations between single nucleotide polymorphisms (SNPs) and breast cancer includes both the novel findings (1-6) and the replication of previously reported low penetrance risk alleles $(3,5,6)$. Work to refine the signal location and assess common variants that did not achieve genome-wide levels of significance (generally accepted to be less than $5 \times 10^{-7}$ ) continues $(1,6)$, providing an opportunity to elucidate the underlying mechanisms by evaluating potential interactions with environmental, occupational, hormonal, or lifestyle risk factors. One approach is to examine variation in risk by genotype based on known breast carcinogens, such as ionizing radiation exposure (7). In addition to providing clues about how the variant may be affecting disease risk, this approach has the potential to identify sub-populations that are susceptible to ionizing radiation exposure. This is an important public health concern, given the more than sevenfold increase in collective medical radiation dose exposure between 1982 and 2006 to the US population (8-10).

We evaluated radiation interaction with new polymorphic variants identified for confirmatory genotyping within the Cancer Genetic Markers of Susceptibility (CGEMS) (6) and the Breast Cancer Association Consortium (BCAC) (1) genome-wide association studies (GWAS) among women occupationally and medically exposed to ionizing radiation from a case-control study that was nested within the U.S. Radiologic Technologists (USRT) cohort. The USRT breast cancer study was a component of CGEMS and BCAC and contributed confirmatory data for the same breast cancer cases and controls as reported here. Ionizing radiation is an established breast cancer carcinogen $(11,12)$, and occupational exposure to ionizing radiation has been previously associated with breast cancer risk in the USRT cohort (13). We specifically hypothesized that the variant in RAD5IL1 (6) may modify the association between breast cancer and radiation as it is upregulated in human lymphocytes at radiation doses as low as $25 \mathrm{cGy}$ (14).

\section{Materials and Methods}

\section{Study population}

In 1982, the U. S. National Cancer Institute, in collaboration with the University of Minnesota and the American Registry of Radiologic Technologists, initiated a study of cancer incidence and mortality among 146,022 (106,953 female) U.S. radiologic technologists who were certified for at least two years between 1926 and 1982. The cohort members are predominantly white (95\%) and their current mean age is 58 years. From 1984 to 1989 and 1993 to 1998 , postal surveys were conducted that included detailed questions related to work history as a radiologic technologist, family history of cancer, reproductive history, height, weight, other cancer risk factors and information regarding health outcomes. 69,524 of 98,233 (71\%) and 69,998 of 94,508 (74\%) known living female technologists responded to the first and second surveys, respectively (15). This study has been approved annually by the human subjects review boards of the National Cancer Institute and the University of Minnesota.

\section{Case and control recruitment}

All living female technologists reporting a primary breast cancer (ductal carcinoma in situ or invasive breast cancer) that was confirmed based on pathology or medical records were eligible for inclusion. In December 1999, when biospecimen collection began, there were 
1386 living (prevalent) breast cancer cases with diagnosis years ranging from 1955 to 1998 . By the end of December 2003, 874 (63\%) breast cancer cases had provided informed consent, a blood sample, and completed a telephone interview collecting updated cancer risk factor and family cancer history information and selected work history data. Controls were technologists who had not reported a diagnosis of breast cancer prior to 1998 and were randomly selected and frequency matched to cases (ratio 1.5:1) by birth year in 5 year strata. Of the 2268 living controls, 1094 (48\%) provided informed consent, a blood sample, and completed a telephone interview. We compared demographic and other characteristics among responders, nonresponders, and decedents and found no differences in education, marital status, alcohol consumption, age at menarche, age at first live birth, and number of live births. However, among cases and controls, the proportion of African-Americans was lower among responders than nonresponders, slightly more responders than nonresponders used oral contraceptives, and a higher percentage of technologists from the Midwest responded compared with those from the Northeast. Decedents who reported a breast cancer but died before blood collection $(N=352)$ were significantly more likely to be older at breast cancer diagnosis, African-American, and smoked cigarettes longer than responders.

\section{Sample handling and SNP selection}

After venipuncture, whole blood samples were shipped overnight with an ice pack to the processing laboratory in Frederick, MD. Blood components were separated and DNA was extracted using Qiagen Kits (Qiagen, Valencia, CA). The samples were tracked by a unique ID code, and laboratory investigators were blinded to case-control status. Due to biospecimen contamination $(\mathrm{N}=12)$, inadequate biospecimen quantity $(\mathrm{N}=12)$ and incomplete survey data $(\mathrm{N}=2)$, the final sample size consisted of 859 cases and 1083 controls. We analyzed 27 variants that were identified by CGEMS and BCAC in their final genotyping rounds $(1,6)$. Certain SNPs were selected by CGEMS for broader regional coverage, such as for MRPS30, and were already known to be in linkage disequilibrium (LD). The 27 SNPs, representing 22 distinct regions, were rs3817198, rs4132417, rs6504950, rs4973768, rs37936, rs930395, rs11077820, rs7121523, rs7936636, rs9491859, rs11249433, rs17570439, rs2303659, rs10941679, rs10483813 (chosen because it is in complete LD with rs999737 for which a Taqman assay could not be designed), rs12608723, rs2067980 (chosen because it has an $\mathrm{r}^{2}=0.50$ with rs 7716600 for which manufacturing failed), rs1774070, rs998592, rs12622050, rs4415084, rs724244, rs2391406, rs4666451, rs10850145, rs3134615, and rs1274466. Genotyping methods have been previously described (2).

\section{Occupational and Personal Diagnostic lonizing Radiation Exposure}

The occupational dosimetry system used to estimate absorbed dose to the breast [in units of Gray (Gy)] has been described in detail elsewhere (16-18), but included some refinements for this work. Briefly, yearly breast doses were derived from badge dose measurements and were summed to derive a cumulative occupational breast dose for each person. Individuals without actual monitoring badge readings were assigned yearly doses using simulation techniques from probability distributions that described the plausible range of doses based on the data from radiologic technologists with badge dose measurements. However, to minimize the uncertainty of estimated doses and the likelihood of dose misclassification, the probability distributions that describe the variability in doses received in a given year by the cohort were partitioned, where possible, into narrower density distributions (high, standard, low) based on work history data. Radiation exposure that occurred within the 10 years prior to breast cancer diagnosis in the cases and an equivalent time period in controls was not included in the cumulative radiation dose. A 10 year lag for exposures was chosen because this is a generally accepted latency period for solid cancers $(12,19,20)$. 
We also derived a cumulative breast dose score as an estimate of organ dose from the numbers and calendar time periods of diagnostic x-ray procedures that study participants reported receiving on the cohort surveys. One unit of dose score approximates one Gy of ionizing radiation absorbed dose. A detailed description of methods used to derive the breast dose score have been previously published (21). For radionuclide and radiation therapy procedures we created "ever/never" variables because information on the number of procedures subjects underwent was not available. For all personal medical procedures, those procedures occurring 10 years prior to breast cancer diagnosis for cases and an equivalent time point for controls were excluded; a 10 year lag also minimizes potential bias from procedures performed because of pre-clinical disease symptoms (22).

\section{Statistical Analysis}

For each SNP, the rare allele among controls was considered the variant allele. We assessed Hardy-Weinberg equilibrium (HWE) among controls using chi-square tests. For genotype main effects we assumed co-dominant and dominant modes of inheritance to assess individual genotype effects and to maximize power to detect effect modification. Associations between SNPs and breast cancer were evaluated using unconditional logistic regression. All p-values are two-sided.

Main effects of occupational breast dose and personal diagnostic radiation breast dose score were assessed by modeling the odds ratio as a linear function in logistic regression models:

$$
\mathrm{OR}=1+\beta \times D
$$

where $D$ is continuous radiation dose and $\beta$ is the excess odds ratio (EOR) per unit dose (Gy) or dose score. Occupational radiation dose and personal diagnostic radiation dose score were adjusted for each other in categories as seen in Table 1. Adjusting for exposure from radiation and radionuclide therapies had little effect on the estimated risks from occupational and personal diagnostic x-ray exposures. All regression models were adjusted for year of birth, but age at menarche, number of live births, age at first birth, family history of breast cancer, history of benign breast disease, oral contraceptive use, hormonal replacement therapy, body mass index, height, alcohol consumption and cigarette smoking did not substantially change genotype estimates, so these variables were not included in the final models. Confidence intervals (CI) for genotype risk estimates were Wald-based while confidence intervals for radiation risk estimates were derived from the profile likelihood method. Unlike OR estimates, EOR estimates are statistically significant when the confidence interval excludes zero. We used the EPICURE software package (Hirosoft, Seattle, WA) for linear dose-response analyses and SAS software (SAS Institute, Cary, North Carolina, Release 8.02) for all other analyses.

To evaluate whether SNPs modified the relation between radiation and breast cancer risk, we allowed the radiation-related EOR to vary by genotype while adjusting for the genotype effect. EOR heterogeneity across genotype categories was assessed using likelihood ratio tests (LRT). Since some genotype categories contained small numbers of individuals, doseresponse estimates were sometimes less than zero and are denoted as " $<0$ ".

\section{Results}

Selected demographic and ionizing radiation exposure variables are summarized in Table 1. Cases were more likely than controls to have had a history of radiation therapy. An increased risk of breast cancer was significantly associated with cumulative occupational radiation absorbed dose to the breast after adjustment for age and personal diagnostic 
radiation exposure $(\mathrm{EOR} / \mathrm{Gy}=3.0,95 \% \mathrm{CI}=0.04-7.8, \mathrm{p}=0.046)$, but not with personal diagnostic radiation breast dose score $(\mathrm{EOR} / \mathrm{Gy}=1.3,95 \% \mathrm{CI}=-0.4-4.0, \mathrm{p}=0.3)$. The two sources of radiation exposure were uncorrelated $\left(r^{2}=0.02\right)$.

The associations between the 27 SNPs and breast cancer in our study have been previously published as part of the BCAC (3 SNPs; Ahmed et al, 2009) and CGEMS (24 SNPs; Thomas et al, 2009) analysis. Among U.S. radiologic technologists, breast cancer risk was statistically significantly associated $(\mathrm{p} \leq 0.05)$ with two SNPs shown in Table 2: the minor allele of STXBP4 (rs6504950; decreased risk) and the linked SNPs in MRPS30 (rs930395, rs10941679, rs4415084; increased risk). We observed no association between rs 10483813 in the RAD51L1 gene and breast cancer risk (Table 2).

Assuming a dominant mode of inheritance, we detected statistically significant interaction with personal diagnostic radiation and the rs $930395 \mathrm{SNP}$ in MRPS30 $\left(\mathrm{P}_{\text {interaction }}=0.04\right)$ (Table 3). No elevated radiation-related breast cancer risk was observed for those homozygous for the common allele, but the EOR/Gy was 3.4 (95\% CI $=0.2-9.2)$ for those with one or more minor alleles. The risk estimates for occupational radiation dose and the rs930395 minor allele were similar in magnitude $(\mathrm{EOR} / \mathrm{Gy}=4.2,95 \% \mathrm{CI}<0-14.4)$, but the test for effect modification did not reach statistical significance ( $p_{\text {interaction }}=0.3$ ). When assuming a dominant mode of inheritance, two of the three other linked SNPs in MRSP3O (rs10941679, rs4415084) showed similar radiation-related breast cancer risks. Other SNPs for which there was suggestive evidence of interaction with ionizing radiation were STXBP4 rs6504950, C6ORF190 rs9491859 and NPAS2 rs12622050. However, we did not see evidence of a main effect of the SNPs in C6ORF190I or NPAS2, and estimates of risk for occupational and personal diagnostic radiation were not consistent for STXBP4. While we observed a suggestive interaction for carrying both minor alleles of RAD51L1 (rs1048381; $p_{\text {interaction }}=0.1$ ), this was based on very small numbers, was not statistically significant in a dominant model, and was only evident for occupational radiation exposure.

\section{Discussion}

Of the 27 SNPs that we analyzed, the statistically significant interactions with radiation dose for SNPs in the MRPS30 gene were the most consistent. It is important to recognize that MRPS30 (alias PDCD9), which is homologous to the pro-apoptotic p52 chicken gene $(23,24)$, encodes a component of the small subunit of the mitochondrial ribosome, and is likely to be involved in pre-apoptotic events (25). Although the exact function of this gene is unknown, the apoptotic pathway is likely to be involved in mitigating DNA damage caused by ionizing radiation. Radiation-induced apoptosis has been shown to occur in response to damage in the nucleus or cytoplasm-membrane $(26,27)$. In normal cells, DNA damage such as that produced by exposure to ionizing radiation is recognized by cellular mechanisms, and responses to prevent the propagation of errors include DNA damage repair, activation of checkpoints to arrest the cell cycle, and cell apoptosis (28). Consistent with the probable importance of these pathways in radiation-induced carcinogenesis, we saw some suggestion of an interaction with radiation dose for a SNP in the NPAS2 gene, a core circadian gene that has been shown to impair DNA repair capacity (29).

Given that the SNPs in this study were chosen as tagging markers for the genetic region and were not based on any known or suspected function, the observed associations could be due to linkage disequilibrium with the true unobserved causal SNPs. Given the multifaceted and closely-linked nature of the DNA repair, cell-cycle and apoptotic pathways, it is likely that there are complex polygenic factors underlying the observed interactions of MRPS30 with occupational and diagnostic radiation exposure. As the number of convincing disease-SNP associations grow, it will be important to conduct further epidemiologic study of their 
potential interaction with established risk factors, ideally in prospective cohort settings where biases may be reduced. Such studies may give direction to guide laboratory analyses that can more definitively evaluate them and eventually lead to clinical applications.

Strengths of the present study include the availability of detailed questionnaire data on reproductive, demographic and lifestyle factors, including medical diagnostic history, and the comprehensive occupational dose reconstruction system that has been supported by biodosimetry in a separate effort (16). Limitations include the use of prevalent rather than incident breast cancer cases; however, the prevalence of genotype frequencies by the time between breast cancer diagnosis and blood collection showed no significant differences (results not shown). A similar analysis considering occupational and personal diagnostic ionizing radiation exposures was not possible because increased survival time was associated with greater age, which is associated with greater cumulative exposure among our study subjects. However, an analysis of all types of cancers among atomic bomb survivors demonstrated no association between survival time and radiation dose (30). Furthermore, except for our hypothesized association and effect modification with $R A D 51 L 1$, this study should be viewed as an exploratory analysis with no prior hypothesis regarding radiation interaction with the other 23 variants. As these were exploratory analyses, we did not correct for multiple testing. Therefore, chance may explain our findings with MRPS30, NPAS2, $S T X B P 4$ and C6ORF190, which need to be confirmed in other populations with low to moderate levels of radiation exposure.

This case-control study nested within the USRT cohort presented a unique opportunity to evaluate effect modification of SNPs conferring susceptibility to breast cancer by ionizing radiation, an established breast cancer carcinogen $(11,12)$. We believe the MRPS30 gene may be a good candidate for functional studies because the risk estimates for the MRPS30SNPs were consistent with the GWAS study (6), carefully reconstructed radiation dose estimates were used, and MRPS30 is related to apoptosis, a known cellular response to ionizing radiation exposure.

\section{Acknowledgments}

We are grateful to the radiologic technologists who participated in the USRT Study; Jerry Reid of the American Registry of Radiologic Technologists for continued support of this study; Diane Kampa and Allison Iwan of the University of Minnesota for study coordination and data collection, and Laura Bowen of Information Management Systems for data management. This project has been funded in part by the National Cancer Institute, National Institutes of Health, under Contract No. HHSN261200800001E, and by the Intramural Research Program of the Division of Cancer Epidemiology and Genetics, National Cancer Institute, National Institutes of Health. The content of this publication does not necessarily reflect the views or policies of the Department of Health and Human Services, nor does mention of trade names, commercial products, or organizations imply endorsement by the U.S. Government.

\section{References}

1. Ahmed S, Thomas G, Ghoussaini M, Healey CS, Humphreys MK, Platte R, Morrison J, Maranian M, Pooley KA, et al. Newly discovered breast cancer susceptibility loci on 3p24 and 17q23.2. Nat Genet 2009;41:585-590. [PubMed: 19330027]

2. Easton DF, Pooley KA, Dunning AM, Pharoah PD, Thompson D, Ballinger DG, Struewing JP, Morrison J, Field H, et al. Genome-wide association study identifies novel breast cancer susceptibility loci. Nature 2007;447:1087-1093. [PubMed: 17529967]

3. Hunter DJ, Kraft P, Jacobs KB, Cox DG, Yeager M, Hankinson SE, Wacholder S, Wang Z, Welch $\mathrm{R}$, et al. A genome-wide association study identifies alleles in FGFR2 associated with risk of sporadic postmenopausal breast cancer. Nat Genet 2007;39:870-874. [PubMed: 17529973]

4. Stacey SN, Manolescu A, Sulem P, Rafnar T, Gudmundsson J, Gudjonsson SA, Masson G, Jakobsdottir M, Thorlacius $S$, et al. Common variants on chromosomes $2 q 35$ and 16q12 confer 
susceptibility to estrogen receptor-positive breast cancer. Nat Genet 2007;39:865-869. [PubMed: 17529974]

5. Stacey SN, Manolescu A, Sulem P, Thorlacius S, Gudjonsson SA, Jonsson GF, Jakobsdottir M, Bergthorsson JT, Gudmundsson J, et al. Common variants on chromosome 5p12 confer susceptibility to estrogen receptor-positive breast cancer. Nat Genet 2008;40:703-706. [PubMed: 18438407]

6. Thomas G, Jacobs KB, Kraft P, Yeager M, Wacholder S, Cox DG, Hankinson SE, Hutchinson A, Wang Z, et al. A multistage genome-wide association study in breast cancer identifies two new risk alleles at 1p11.2 and 14q24.1 (RAD51L1). Nat Genet 2009;41:579-584. [PubMed: 19330030]

7. Bhatti P, Doody MM, Alexander BH, Yuenger J, Simon SL, Weinstock RM, Rosenstein M, Stovall $\mathrm{M}$, Abend M, et al. Breast cancer risk polymorphisms and interaction with ionizing radiation among U.S. radiologic technologists. Cancer Epidemiol Biomarkers Prev 2008;17:2007-2011. [PubMed: 18708391]

8. Brenner DJ, Hall EJ. Computed tomography--an increasing source of radiation exposure. N Engl J Med 2007;357:2277-2284. [PubMed: 18046031]

9. Mettler FA Jr. Thomadsen BR, Bhargavan M, Gilley DB, Gray JE, Lipoti JA, McCrohan J, Yoshizumi TT, Mahesh M. Medical radiation exposure in the U.S. in 2006: preliminary results. Health Phys 2008;95:502-507. [PubMed: 18849682]

10. National Council on Radiation Protection and Measurements. and National Council on Radiation Protection and Measurements. Ionizing radiation exposure of the population of the United States. National Council on Radiation Protection and Measurements; Bethesda, Md: 2009. Scientific Committee 6-2 on Radiation Exposure of the U.S. Population.

11. Ronckers CM, Erdmann CA, Land CE. Radiation and breast cancer: a review of current evidence. Breast Cancer Res 2005;7:21-32. [PubMed: 15642178]

12. United Nations. Sources and effects of ionizing radiation : United Nations Scientific Committee on the Effects of Atomic Radiation : UNSCEAR 2000 report to the General Assembly, with scientific annexes. United Nations; New York: 2000. Scientific Committee on the Effects of Atomic Radiation.

13. Doody MM, Freedman DM, Alexander BH, Hauptmann M, Miller JS, Rao RS, Mabuchi K, Ron E, Sigurdson AJ, Linet MS. Breast cancer incidence in U.S. radiologic technologists. Cancer 2006;106:2707-2715. [PubMed: 16639729]

14. Fachin AL, Mello SS, Sandrin-Garcia P, Junta CM, Donadi EA, Passos GA, Sakamoto-Hojo ET. Gene expression profiles in human lymphocytes irradiated in vitro with low doses of gamma rays. Radiat Res 2007;168:650-665. [PubMed: 18088177]

15. Sigurdson AJ, Doody MM, Rao RS, Freedman DM, Alexander BH, Hauptmann M, Mohan AK, Yoshinaga S, Hill DA, et al. Cancer incidence in the US radiologic technologists health study, 1983-1998. Cancer 2003;97:3080-3089. [PubMed: 12784345]

16. Bhatti P, Preston DL, Doody MM, Hauptmann M, Kampa D, Alexander BH, Petibone D, Simon SL, Weinstock RM, et al. Retrospective biodosimetry among United States radiologic technologists. Radiat Res 2007;167:727-734. [PubMed: 17523852]

17. Bhatti P, Struewing JP, Alexander BH, Hauptmann M, Bowen L, Mateus-Pereira LH, Pineda MA, Simon SL, Weinstock RM, et al. Polymorphisms in DNA repair genes, ionizing radiation exposure and risk of breast cancer in U.S. Radiologic technologists. Int J Cancer 2008;122:177-182. [PubMed: 17764108]

18. Simon SL, Weinstock RM, Doody MM, Neton J, Wenzl T, Stewart P, Mohan AK, Yoder RC, Hauptmann M, et al. Estimating historical radiation doses to a cohort of U.S. radiologic technologists. Radiat Res 2006;166:174-192. [PubMed: 16808606]

19. Land CE. Temporal distributions of risk for radiation-induced cancers. J Chronic Dis 1987;40(Suppl 2):45S-57S. [PubMed: 3312274]

20. National Research Council (U.S.). Health risks from exposure to low levels of ionizing radiation : BEIR VII Phase 2. National Academies Press; Washington, D.C.: 2006. Committee to Assess Health Risks from Exposure to Low Level of Ionizing Radiation.

21. Sigurdson AJ, Bhatti P, Doody MM, Hauptmann M, Bowen L, Simon SL, Weinstock RM, Linet MS, Rosenstein M, et al. Polymorphisms in apoptosis- and proliferation-related genes, ionizing 
radiation exposure, and risk of breast cancer among U.S. Radiologic Technologists. Cancer Epidemiol Biomarkers Prev 2007;16:2000-2007. [PubMed: 17932347]

22. Boice JD Jr. Morin MM, Glass AG, Friedman GD, Stovall M, Hoover RN, Fraumeni JF Jr. Diagnostic X-ray procedures and risk of leukemia, lymphoma, and multiple myeloma. JAMA 1991;265:1290-1294. [PubMed: 2053936]

23. Carim L, Sumoy L, Nadal M, Estivill X, Escarceller M. Cloning, expression, and mapping of PDCD9, the human homolog of Gallus gallus pro-apoptotic protein p52. Cytogenet Cell Genet 1999;87:85-88. [PubMed: 10640817]

24. Sun L, Liu Y, Fremont M, Schwarz S, Siegmann M, Matthies R, Jost JP. A novel 52 kDa protein induces apoptosis and concurrently activates c-Jun N-terminal kinase 1 (JNK1) in mouse C3H10T1/2 fibroblasts. Gene 1998;208:157-166. [PubMed: 9524256]

25. Cavdar Koc E, Ranasinghe A, Burkhart W, Blackburn K, Koc H, Moseley A, Spremulli LL. A new face on apoptosis: death-associated protein 3 and PDCD9 are mitochondrial ribosomal proteins. FEBS Lett 2001;492:166-170. [PubMed: 11248257]

26. Guo M, Chen C, Vidair C, Marino S, Dewey WC, Ling CC. Characterization of radiation-induced apoptosis in rodent cell lines. Radiat Res 1997;147:295-303. [PubMed: 9052675]

27. Haimovitz-Friedman A. Radiation-induced signal transduction and stress response. Radiat Res 1998;150:S102-108. [PubMed: 9806613]

28. Alberts, B. Molecular biology of the cell. Garland Science; New York: 2002.

29. Hoffman AE, Zheng T, Ba Y, Zhu Y. The circadian gene NPAS2, a putative tumor suppressor, is involved in DNA damage response. Mol Cancer Res 2008;6:1461-1468. [PubMed: 18819933]

30. Radiation Effects Research Foundation. Update: Radiation Effects Research Foundation New and Views. 2002. Facts and Figures: Effect of AHS Participation on Cancer Survival. 


\section{Table 1}

Demographic and ionizing radiation exposure variable distributions among breast cancer cases and controls, US Radiologic Technologists study

\begin{tabular}{|c|c|c|c|c|}
\hline Characteristic & Cases $(\%)(n=859)$ & Controls $(\%)(n=1083)$ & p-value ${ }^{a}$ & p-trend $b$ \\
\hline \multicolumn{5}{|c|}{ Ethnicity } \\
\hline Caucasian & $842(98)$ & $1048(97)$ & 0.2 & $\mathrm{~N} / \mathrm{A}^{c}$ \\
\hline African American & $9(1)$ & $18(2)$ & & \\
\hline Other & $8(1)$ & $17(2)$ & & \\
\hline \multicolumn{5}{|c|}{ Year of Birth } \\
\hline$\leq 1925$ & $120(14)$ & $138(13)$ & 0.9 & 0.7 \\
\hline $1926-1935$ & $195(23)$ & $249(23)$ & & \\
\hline $1936-1945$ & $292(34)$ & $382(35)$ & & \\
\hline$>1945$ & $252(29)$ & $314(29)$ & & \\
\hline \multicolumn{5}{|c|}{ Occupational Ionizing Radiation Breast Dose (Gy) } \\
\hline 0 to 0.05 & $687(80)$ & $894(83)$ & 0.2 & 0.1 \\
\hline$>0.05$ to 0.1 & $90(10)$ & $100(9)$ & & \\
\hline$>0.1$ to 0.2 & $63(7)$ & $76(7)$ & & \\
\hline$>0.2$ & $19(2)$ & $13(1)$ & & \\
\hline \multicolumn{5}{|c|}{ Personal Diagnostic Radiation Breast Dose Score } \\
\hline 0 to 0.05 & $686(80)$ & $908(84)$ & 0.1 & 0.05 \\
\hline$>0.05$ to 0.1 & $106(12)$ & $104(10)$ & & \\
\hline$>0.1$ to 0.2 & $46(5)$ & $51(5)$ & & \\
\hline$>0.2$ & $21(2)$ & $20(2)$ & & \\
\hline \multicolumn{5}{|c|}{ Radionuclide Procedures } \\
\hline Never & $721(84)$ & $937(87)$ & 0.3 & NA \\
\hline Ever & $65(8)$ & $71(7)$ & & \\
\hline Unknown & $73(9)$ & $75(7)$ & & \\
\hline \multicolumn{5}{|c|}{ Radiation Therapy } \\
\hline Never & $803(94)$ & $1021(94)$ & 0.01 & NA \\
\hline Ever & $24(3)$ & $14(1)$ & & \\
\hline Unknown & $32(4)$ & $48(4)$ & & \\
\hline \multicolumn{5}{|l|}{ Chi-square test } \\
\hline \multicolumn{5}{|c|}{${ }^{b}$ Mantel-Haenszel trend test } \\
\hline
\end{tabular}




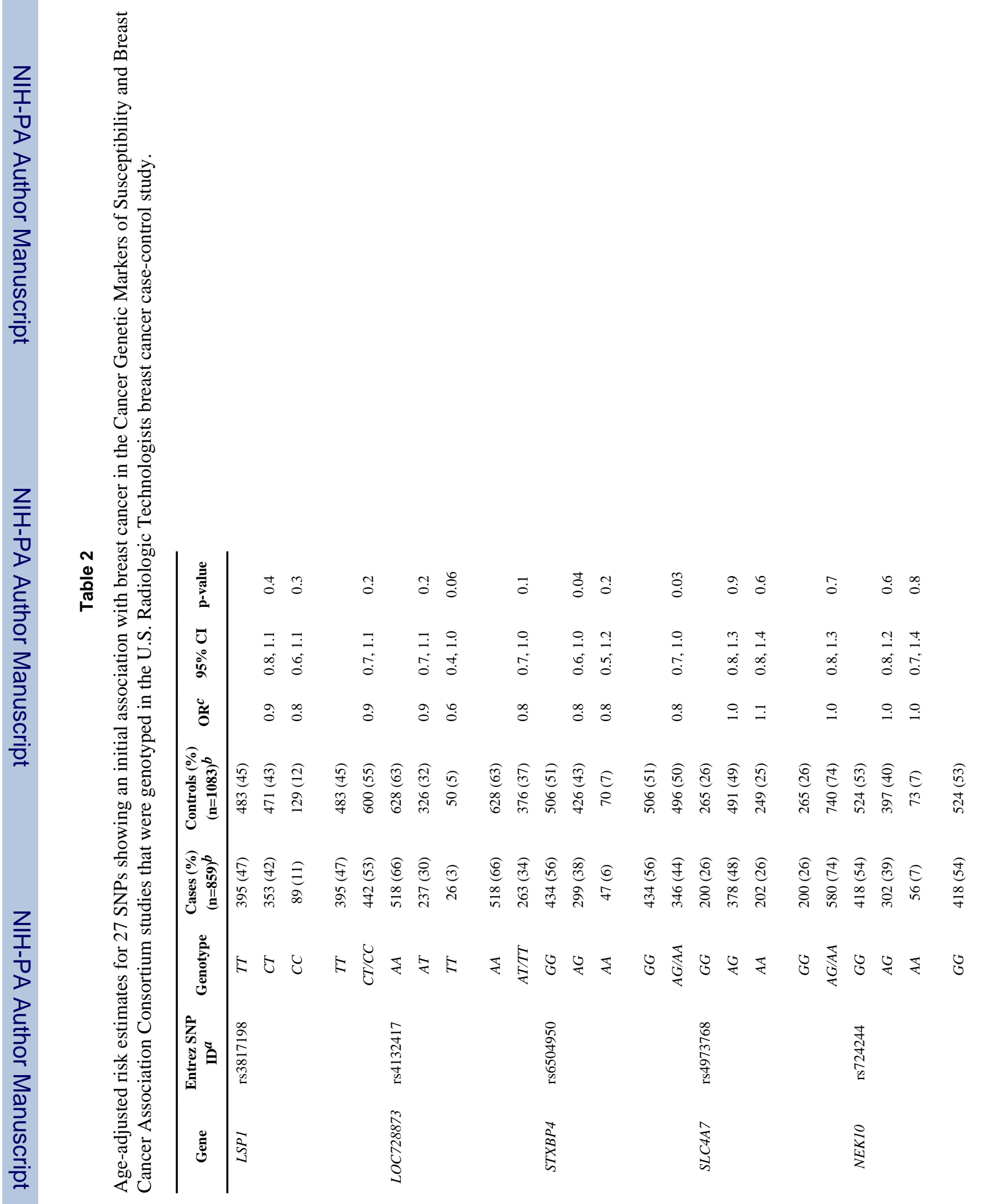




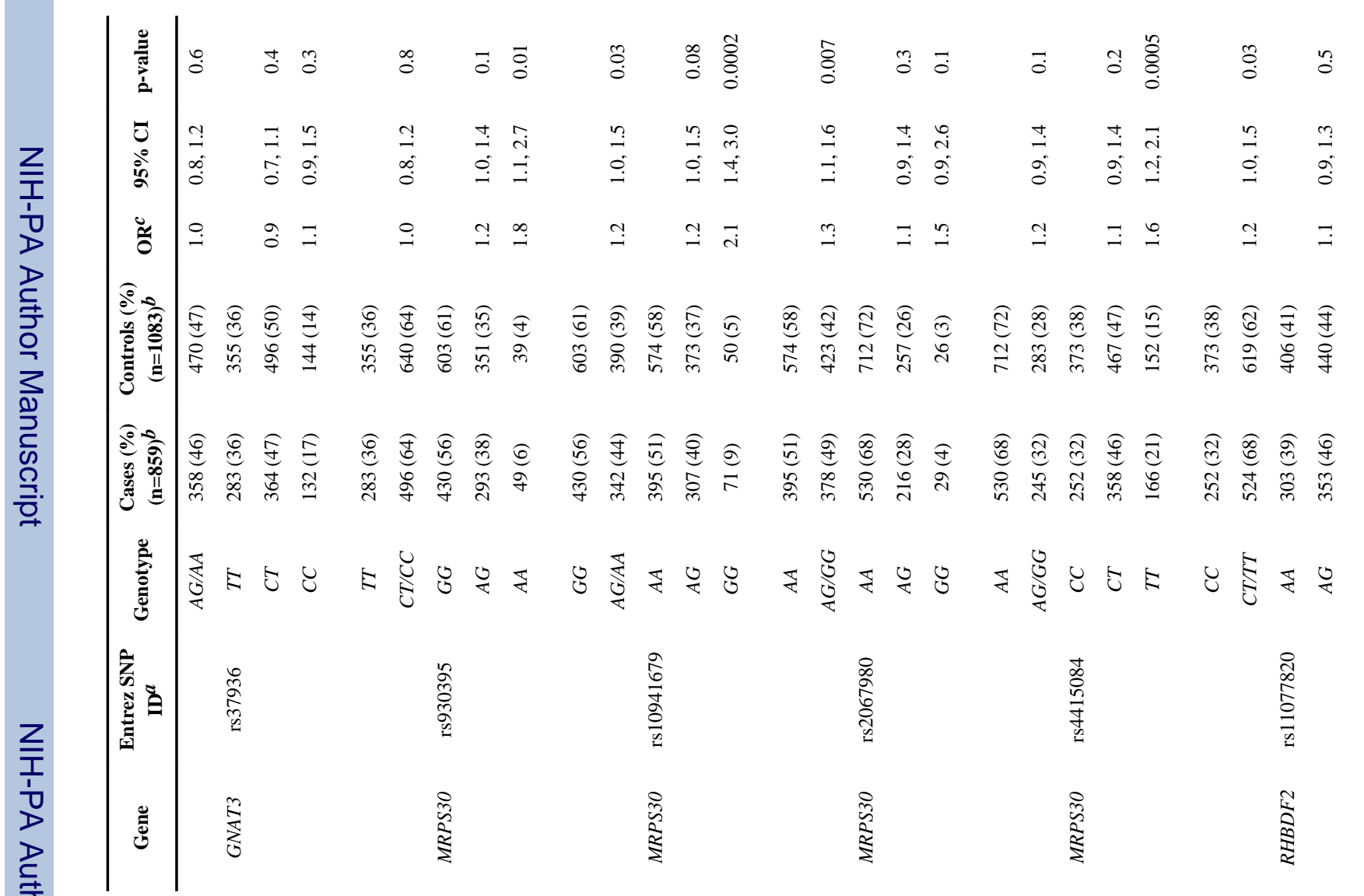


Bhatti et al.

Page 12

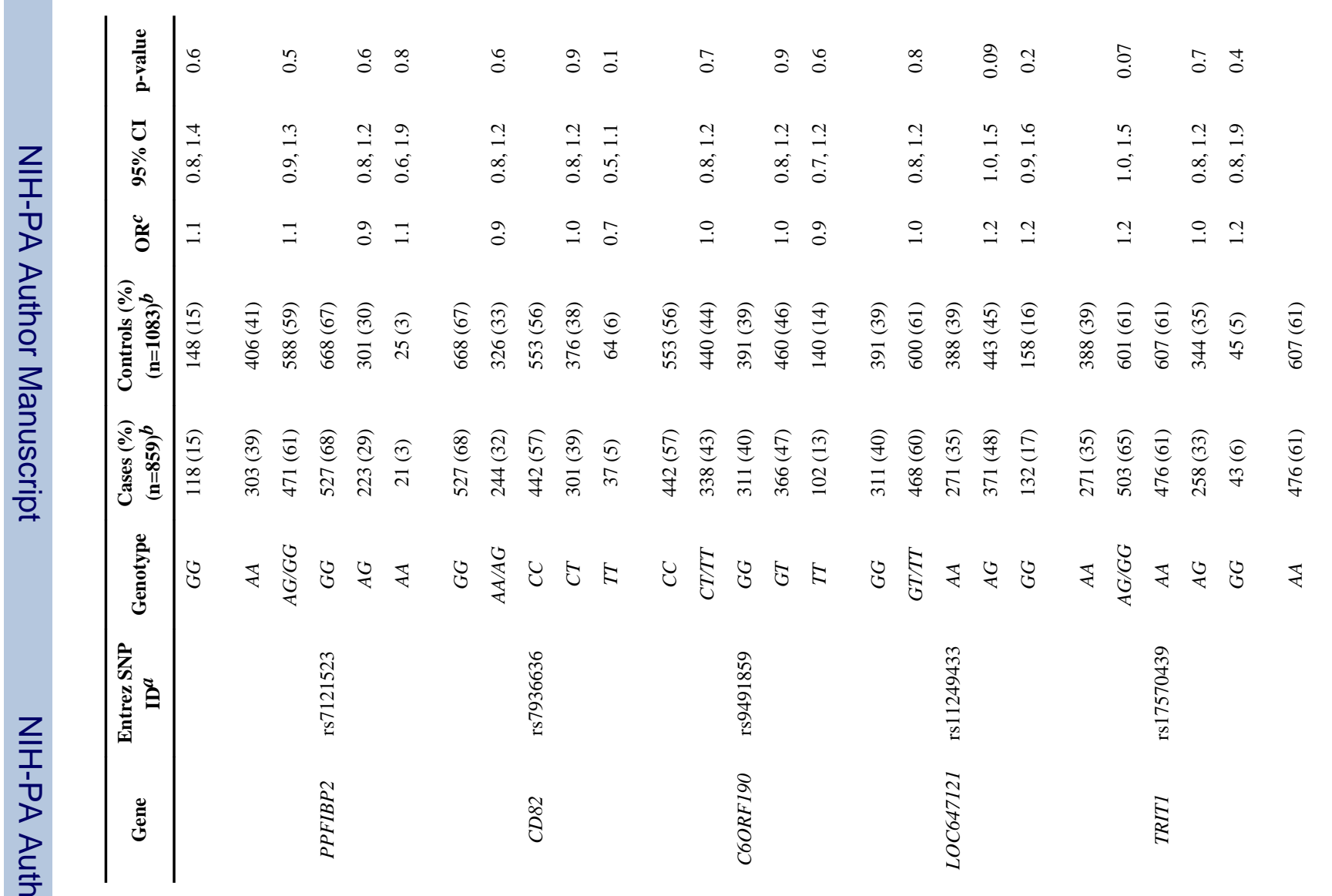




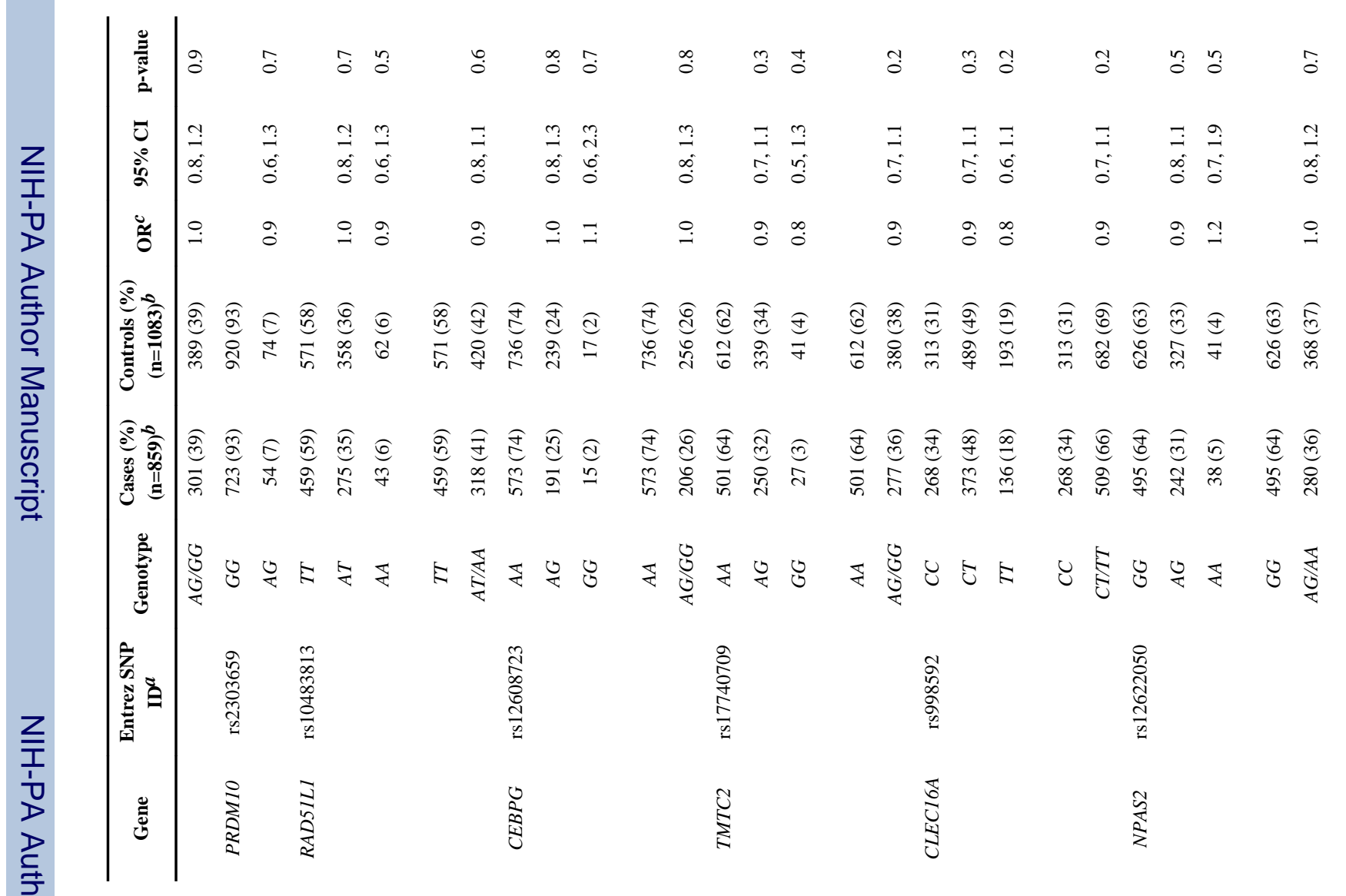


Bhatti et al.

Page 14

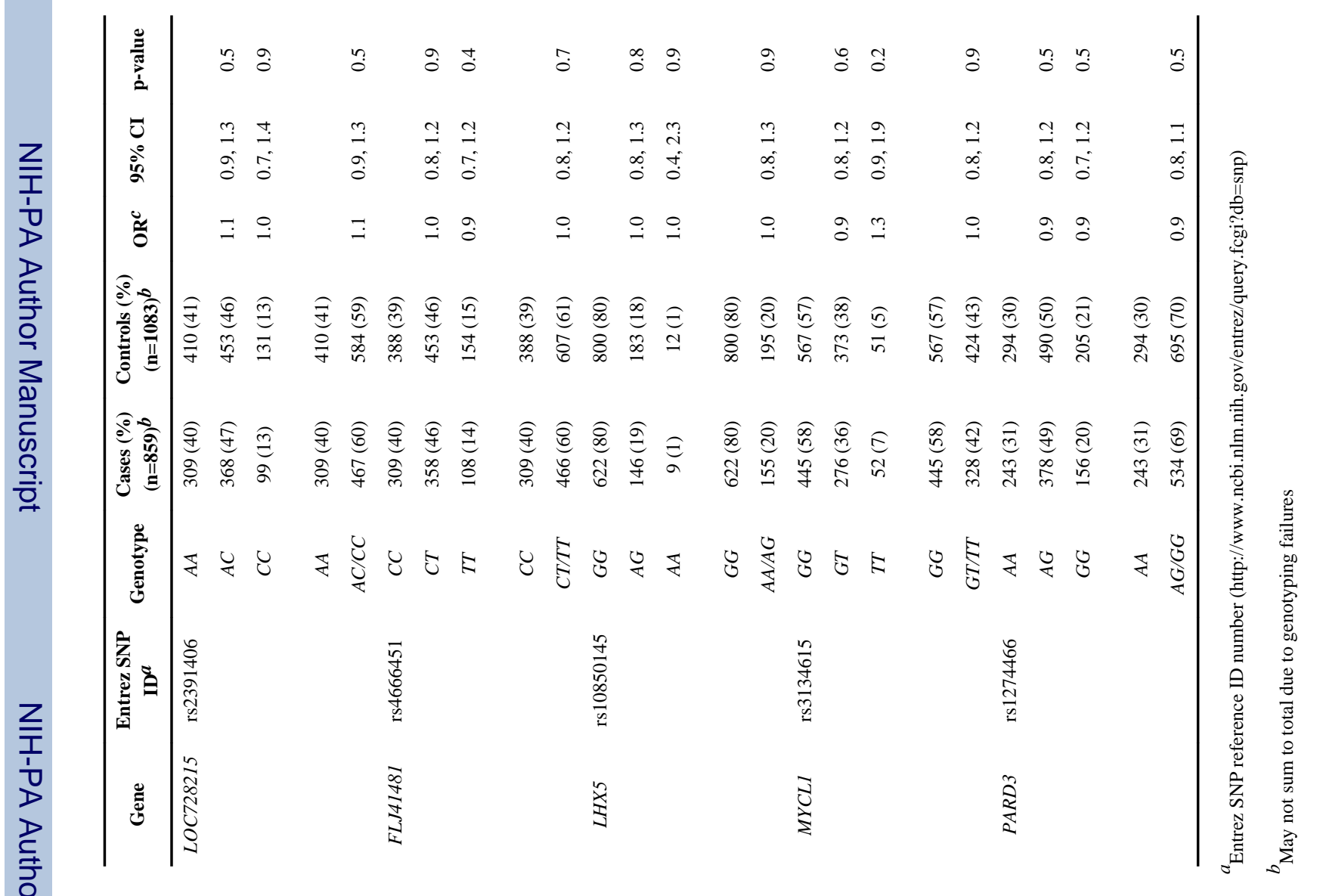




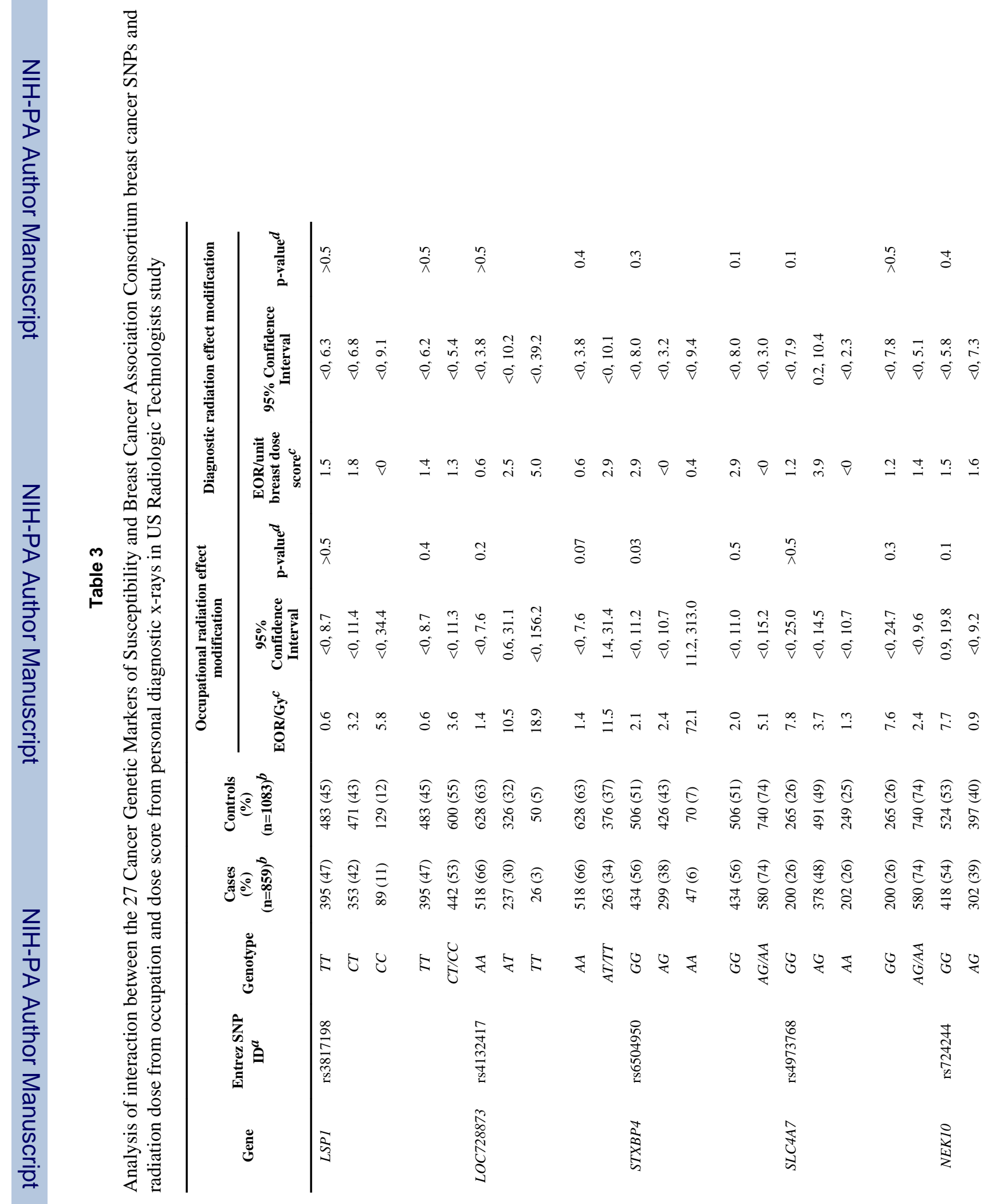




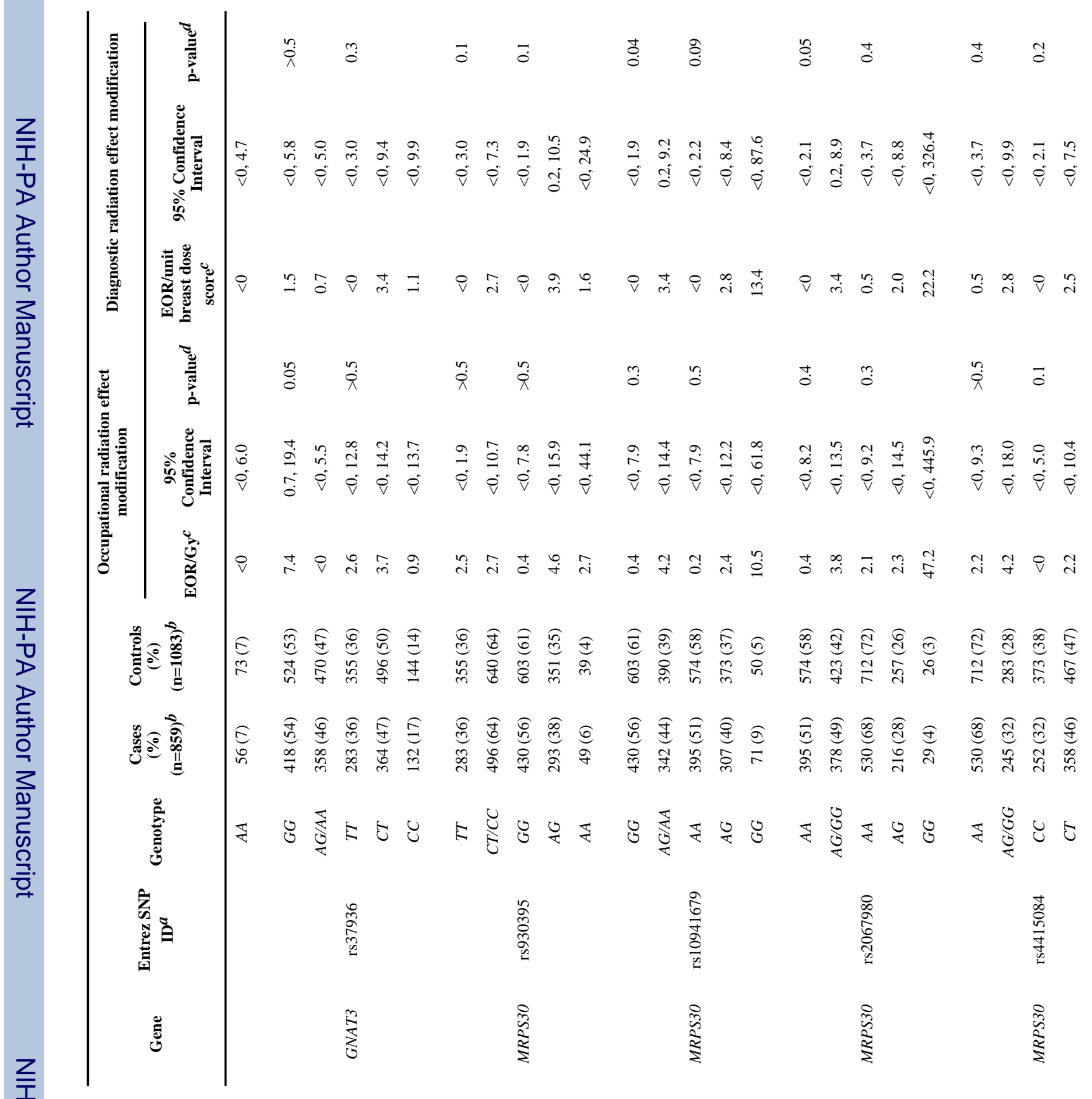




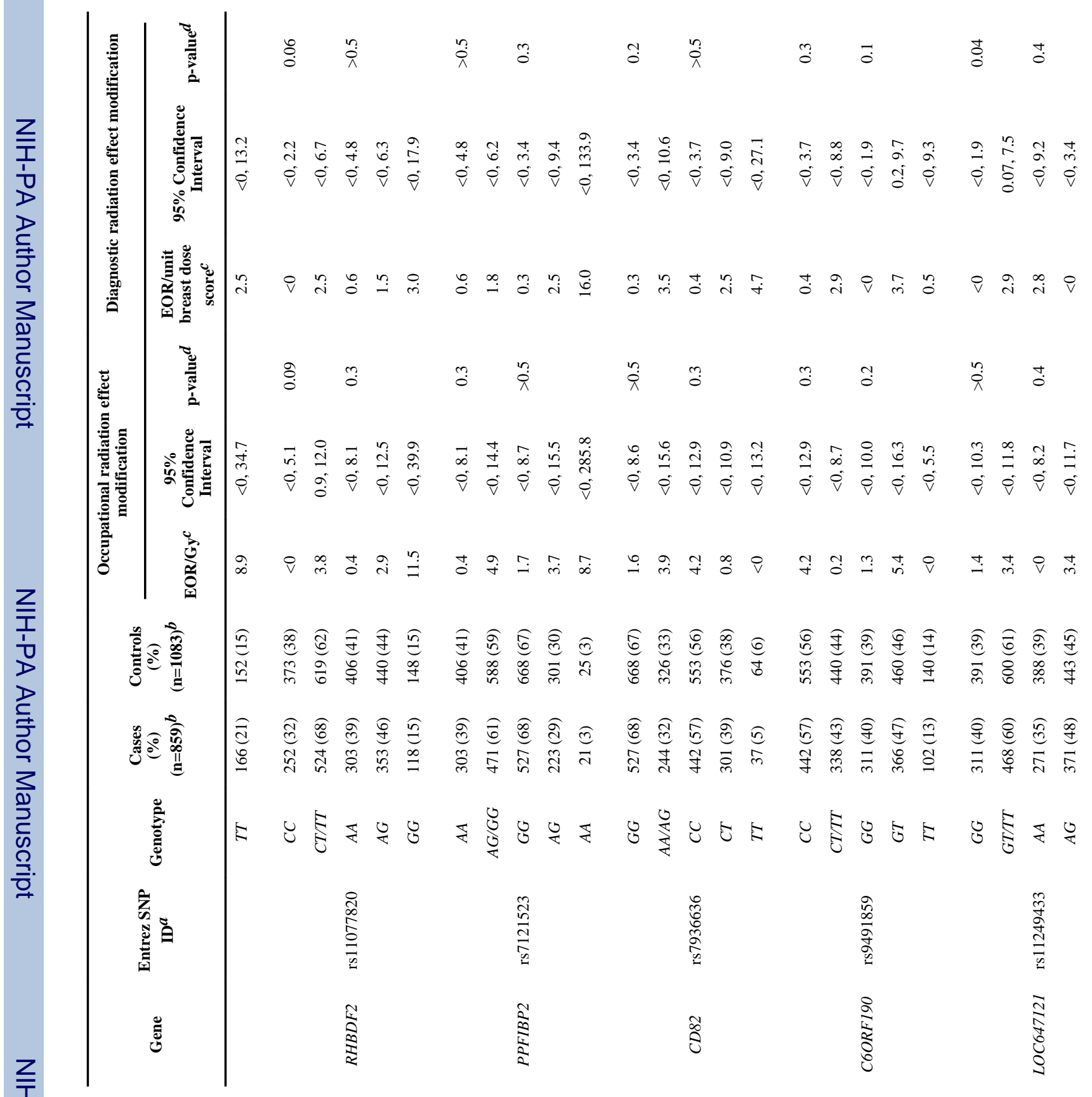




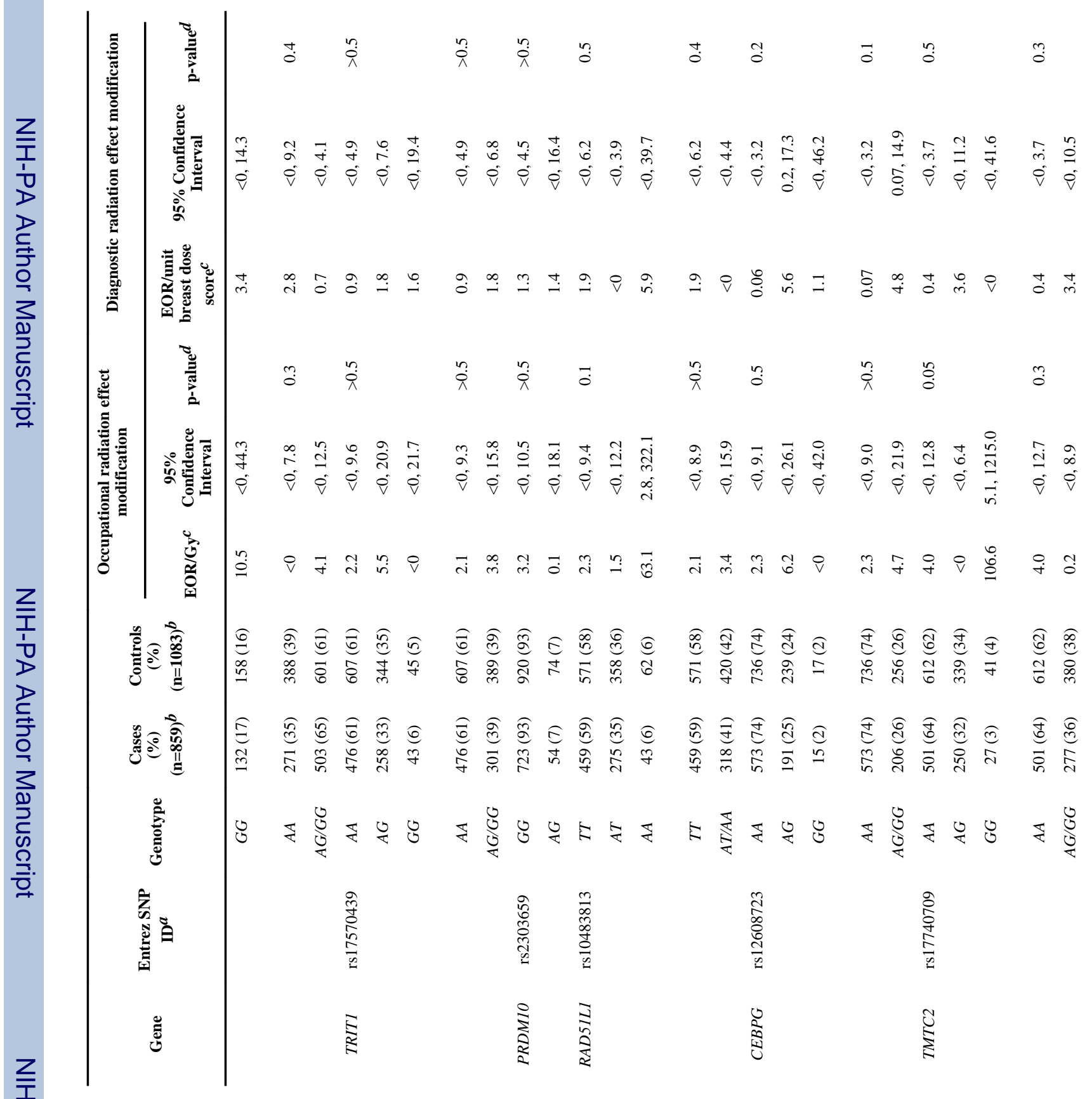




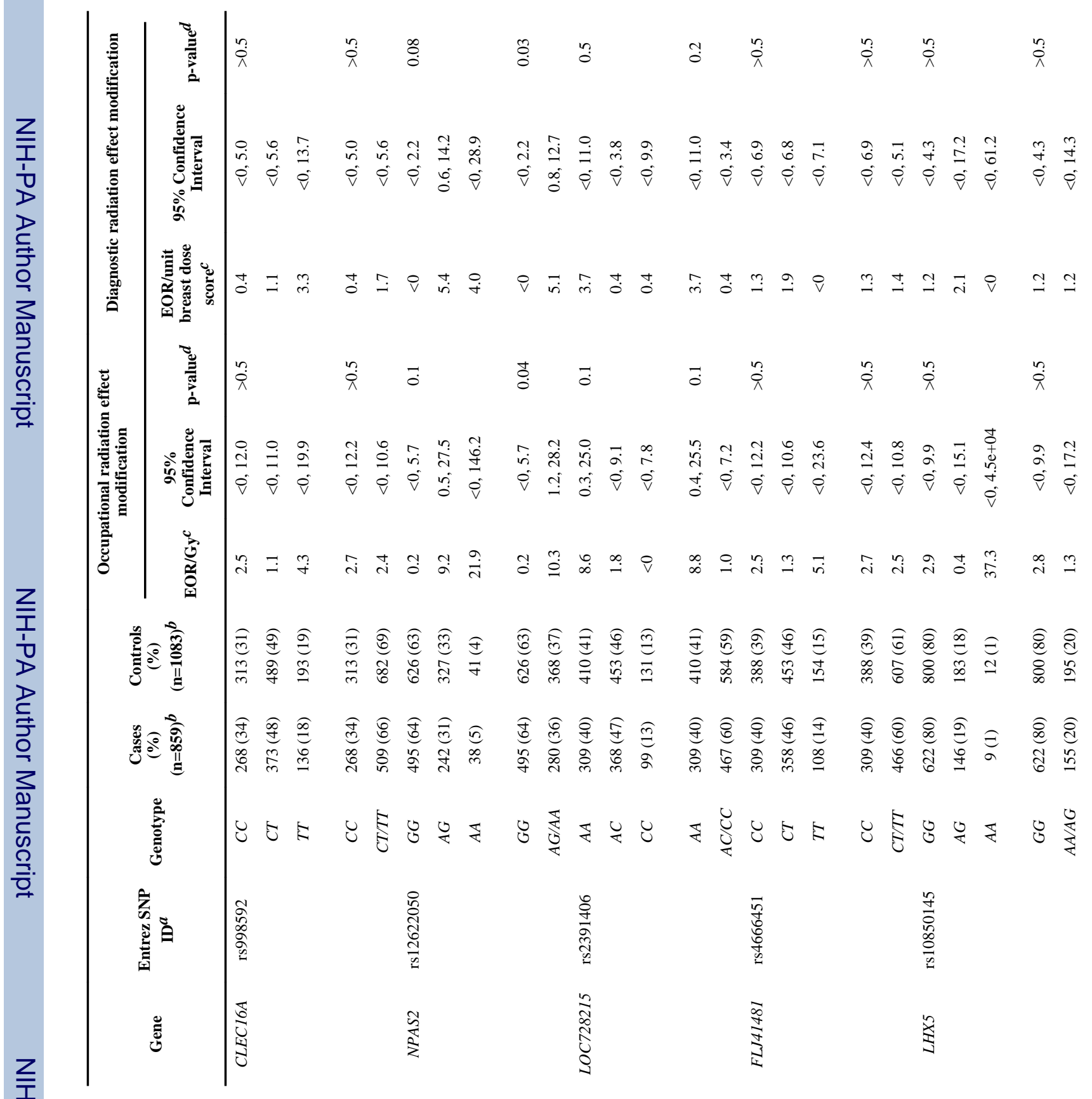




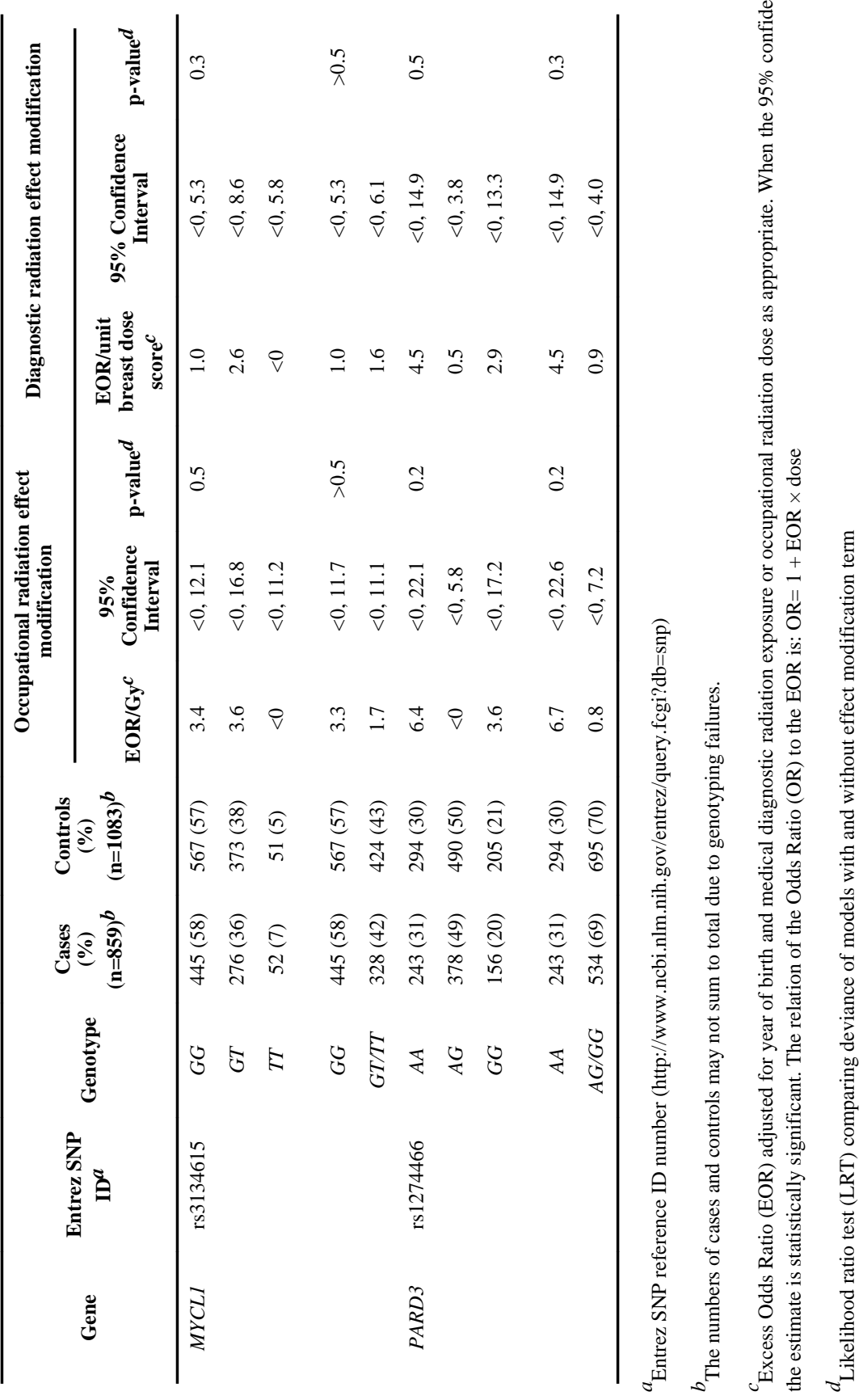

